\title{
Detection of Undeclared Halogen Substituted Drug Compound in a Natural Health Product
}

\author{
Paula N. Brown (D), $\mathrm{PHD}^{1,2^{*}}$, Michael Chan $\mathbb{D}^{\mathrm{D}}, \mathrm{PHD}^{1}$, Chuck Chang, $\mathrm{BSC}^{3}$, Sheena Kuo, $\mathrm{BSc}^{3}$, \\ Yoon Seok Roh, Bsc ${ }^{3}$, James Neal-Kababick ${ }^{4}$, Mary L. Hardy, MD ${ }^{5}$ \\ ${ }^{1}$ Centre for Applied Research \& Innovation, British Columbia Institute of Technology, Burnaby, BC, Canada, V5G3H2 \\ 2Department of Biology, University of British Columbia, Kelowna, BC, Canada \\ ${ }^{3}$ Isura, 501-3292 Production Way, Burnaby, BC, V5A4R4 \\ ${ }^{4}$ Flora Research Laboratories LLC, 1000 SE M Street Unit B, Grants Pass, Oregon, USA, 97526 \\ ${ }^{5}$ Academy of Integrative Health \& Medicine, 6919 La Jolla Blvd., La Jolla, CA 92037 \\ *a Corresponding Author: Paula_Brown@bcit.ca
}

\begin{abstract}
INTRODUCTION: The U-Dream line of products are marketed as natural health product sleep aids in Canada and as dietary supplements in the United States. Several user reviews of the product mention concerning side effects not typically associated with the listed herbal ingredients stated on the product label. Based on these concerns an analytical study was undertaken to determine if the products contained any undeclared pharmaceuticals.
\end{abstract}

METHODS: Product was screened by high resolution mass spectrometry (HRMS) for known pharmaceuticals with sedative and sleep promoting properties. Based on the mass spectral screens an unknown compound was isolated for characterization by nuclear magnetic resonance (NMR) and presence confirmed by Enzymelinked Immunosorbent Assay (ELISA).

RESULTS: The mass spectral analyses indicated the presence of an undeclared analogue of the pharmaceutical drug zopiclone within the product lot tested. NMR characterization confirmed the compound to be a brominated analogue of zopiclone and a commercial zopiclone/eszopiclone ELISA kit tested positive.

DISCUSSION: The undeclared compound was found to be an analogue of zopiclone whereby the chlorine atom was substituted with bromine. Given the results of the ELISA assay and the structural similarity to zopiclone it is likely the compound exhibits biological activity. Of considerable concern is not only the potential of the unknown compound to exhibit pharmacological activity, but the lack of a safety profile by which the risk can be properly assessed.

CONCLUSIONS: The natural health product regulations provide a framework for high quality, safe and efficacious products to access the market. It is the responsibility of the manufacturer to assure traceability and transparency in their supply chain and establish verifiable compliance with GMP. This study illustrates the importance of careful evaluation of analytical data in order to detect undeclared adulterants and highlights the need for an active monitoring and surveillance system for potentially high-risk products.

KEYWORDS: Adulteration; herbal sleep-aid; natural health product; zopiclone

\section{Introduction}

Natural Health Products (NHPs) in Canada are defined and subject to the requirements set out in the Natural Health Products Regulations and include vitamins and minerals, herbal remedies, homeopathic medicines, traditional medicines, probiotics and other products like amino acids and essential fatty acids and are restricted to oral, topical or sublingual routes of administration [1]. 


\title{
Search results
}

\begin{abstract}
From Health Canada
Note - The product information found within this database originates from organizations not subject to the Official Languages Act and is available in the language in which it was written and submitted to Health Canada
\end{abstract}

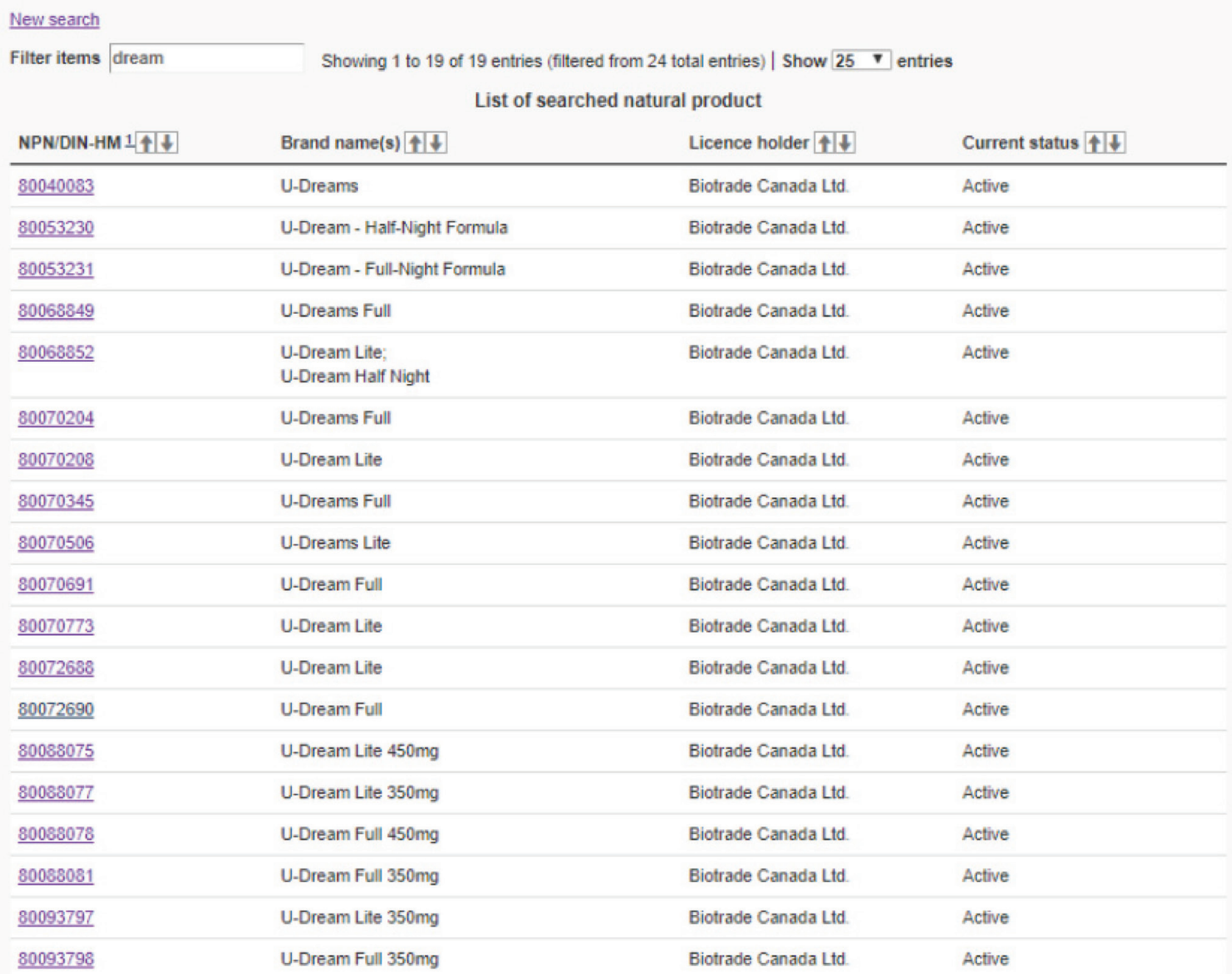

Figure 1. List of U-Dream products licensed as natural health products in Canada as of August 23, 2019 as shown in the NNHPD's Licensed Natural Health Product Database [17].

These products cannot be prescription products, drugs administered by puncturing the skin or any substance that is regulated under the Tobacco or the Controlled Drugs and Substances Acts of Canada [2]. Although these products are considered a subset of drugs, they are exempt from many of the requirements in the Food and Drugs Regulations unless specifically referenced in the Natural Health Products Regulations under the authority of the Natural and Non-prescription Health Products Directorate (NNHPD) [1]. All manufacturers, packagers, labellers and importers of natural health products are required to hold a site license, for which they must demonstrate that they are in compliance with the Good Manufacturing Practices (GMP) requirements set out in the regulations [1]. NHPs are required to undergo a premarket approval process and obtain a license prior to entering the market [1].

Under the existing regulatory framework post-market activities for NHPs are predominately risk-based and complaint driven. In a Health Canada report published in 2016, it recommended the use of proactive tools including inspections to balance the current paper-based licensing process [3]. While Health Canada does engage in a number of post-market activities to limit potential health risks to Canadians, the 2016 report acknowledges that challenges remain with the largely reactive approach, recommending conducting on-site inspections, more laboratory testing as part of compliance 
verification, and the need for stronger post-market authority [3].

Overall NHPs are low risk, can be beneficial and are generally safe, when manufactured in accordance with good manufacturing practices and used as recommended [4-8]. However, adulteration, whereby products contain substances that are not declared on the label but were intentionally added during manufacture, can raise the risk associated with NHP use [3, 9-16]. The presence of undeclared pharmaceuticals has been reported in the literature, in particular with products marketed for weight loss, sports performance/muscle building, sexual performance and to a lesser degree sleep problems, inflammatory conditions and metabolic diseases [10-16].

The U-Dream line of products are licensed natural health products (NHPs) marketed in Canada by Biotrade Canada Ltd. and are sold as over the counter sleep aids (Figure 1) [17]. As of October 10 2019, the U-Dream Full Night product with Natural Health Product Number (NPN) 80070691 holds the \#3 Amazon Bestsellers Rank in Medicinal Sleep Aids [18]. As of August $23^{\text {rd }}, 2019$, this line of products is also present as a dietary supplement in the United States through amazon.com [19].

The product is purported to be an all-natural herbal medicine consisting of several botanical extracts and L-tryptophan. There are different formulations of the U-Dream product on the Canadian market with slight differences in presence and levels of declared herbal medicinal ingredients; as an example the medicinal ingredients for the U-dream Full product with NPN 80088078 and U-Dream Full with NPN 80070691 are shown in Tables 1 and 2. All U-Dream products state they are $100 \%$ natural, and products with different NPN license numbers have essentially the same external packaging color, style, and design.

The U-Dream products have found significant success in the market with many reviews touting their effectiveness as a sleep aid. However, some testimonials associated with the product are concerning such as consumers describing symptoms not typically associated with the listed ingredients, reports that the product left a metallic taste in the mouth following ingestion with others describing serious withdrawal symptoms after only short-term use $[18,19]$. These effects are not included in the cautions or risk warnings for the product and are more typically associated with prescription pharmaceuticals rather than an over-the-counter NHP. With concerns for the risk to public health, an investigation of the product to screen for undeclared pharmaceutical ingredients was initiated with an initial focus on known prescription drugs used to
Table 1. Medicinal ingredients listed in U-Dream full $450 \mathrm{mg}$ product with NPN 80088078.

\begin{tabular}{lc}
\hline Medicinal ingredient & Quantity per capsule \\
\hline Pasiflora incarnate 8:1 extract & $110.0 \mathrm{mg}$ \\
Hesperidin & $85.5 \mathrm{mg}$ \\
Eriabotrya japonica 8:1 extract & $65.0 \mathrm{mg}$ \\
Ziziphus jujube 10:1 extract & $45.0 \mathrm{mg}$ \\
Hericum erinaceus 8:1 extract & $30.0 \mathrm{mg}$ \\
L-Tryptophan & $30.0 \mathrm{mg}$ \\
Schisandra chinensis 7:1 & $25.0 \mathrm{mg}$ \\
Curcumin & $18.0 \mathrm{mg}$ \\
Reynoutria multiflora 5:1 extract & $15.0 \mathrm{mg}$ \\
Rehmannia.glutinosa 5:1 extract & $15.0 \mathrm{mg}$ \\
\hline
\end{tabular}

Table 2. Medicinal Ingredients Listed in U-Dream Full product with NPN 80070691.

\begin{tabular}{lc}
\hline Medicinal Ingredient & Quantity per capsule \\
\hline Pasiflora incarnate 8:1 extract & $110.0 \mathrm{mg}$ \\
Eriabotrya japonica 15:1 extract & $65.0 \mathrm{mg}$ \\
Ziziphus jujube 10:1 extract & $45.0 \mathrm{mg}$ \\
Hericum erinaceus 8:1 extract & $35.0 \mathrm{mg}$ \\
Schisandra chinensis 7:1 & $35.0 \mathrm{mg}$ \\
L-Tryptophan & $30.0 \mathrm{mg}$ \\
Reynoutria multiflora 5:1 extract & $15.0 \mathrm{mg}$ \\
Rehmannia glutinosa 5:1 extract & $15.0 \mathrm{mg}$ \\
\hline
\end{tabular}

treat insomnia such as Lorazepam. Preliminary screens of the product did not detect known pharmaceutical sleep aids but more detailed analysis indicated the presence of an unknown suspicious compound. This paper describes the further analytical efforts made to determine the identity of this unknown, undeclared compound.

\section{Methods}

Solvents and reagents for the analytical work (Formic acid, LC grade methanol, acetonitrile) were purchased from VWR (Edmonton, AB, CAN), Sigma-Aldrich (Oakville, ON, CAN) and Fisher Scientific (Ottawa, $\mathrm{ON}, \mathrm{CAN})$. U-dream capsules were obtained from a local store in Burnaby, British Columbia, Canada. Two products were obtained, U-Dream Full $450 \mathrm{mg}$, NPN 80088078, lot number UDF008 and U-Dream Full, NPN 80070691, lot number UDF004.

\section{Mass Spectral Analysis for Lorazepam}

An intact sealed capsule was removed from the product package and analyzed for the presence of lorazepam. Approximately $100 \mathrm{mg}$ of powder was extracted in acetonitrile:water (1:1) using sonication followed 
by centrifugation and filtration. A duplicate sample was prepared from the same capsule. A third aliquot was prepared in the same manner after spiking with a lorazepam certified reference material at $500 \mu \mathrm{g} / \mathrm{g}$. The aliquots were analyzed on an Agilent 1290 HPLC coupled to an Agilent 6540 Accurate Mass Q-ToF (Agilent Technologies, Mississauga, ON, CAN) running in Auto MS/MS mode. The gradient conditions are as follows: $95 / 5 \mathrm{H}_{2} \mathrm{O}-\mathrm{MeCN}$ to $95 \% \mathrm{MeCN}$ over 12 minutes, hold for $1 \mathrm{~min}$ at $95 \% \mathrm{MeCN}$, return to initial gradient conditions and equilibrate for $4 \mathrm{~min}$ utes at a flow rate of $0.5 \mathrm{ml} /$ minute. Separation is achieved on an Agilent Poroshell 120 SB-C18, $2.7 \mu \mathrm{m}$, $2.1 \mathrm{~mm} \times 100 \mathrm{~mm}$ column (Agilent Technologies, Mississauga, ON, CAN) with a column temperature at $30^{\circ} \mathrm{C}$. Data was analyzed against the Scripps Institute Metlin Accurate Mass (PCDL) Database (Scripps Research, La Jolla, CA, USA) and was also compared to a standard prepared from a new lorazepam certified reference material (Cerilliant Corp., Round Rock, TX, USA). An examination to determine if lorazepam glucuronide was present in the sample was also conducted through extraction of the characteristic $\mathrm{M}+\mathrm{H}$ ion and comparisons to the Metlin PCDL Database. The mass spectral data acquired was screened in Mass Hunter (V6.0, Agilent Technologies, Mississauga, ON, CAN) to find discrete chemical entities; auto MS/MS "find compound" mode.

\section{HR-LCMS Screening for Undeclared Compounds}

For each U-Dream product package, all capsules were opened and the contents, a yellow powder, pooled. $50 \mathrm{mg}$ of the pooled powder was weighed into a $15-\mathrm{mL}$ polypropylene tube and $1600 \mu \mathrm{L}$ of methanol and $400 \mu \mathrm{L}$ of water added using volumetric pipettes. Samples were mixed on a vortex mixer for 10 seconds and centrifuged at 3,000 $\mathrm{g}$ for 5 minutes. The supernatant was filtered through a $0.2-\mu \mathrm{m}$ syringe filter into a microcentrifuge tube, then centrifuged at $15000 \mathrm{~g}$ for 5 minutes. The supernatant was then transferred to an HPLC sample vial for analysis. Samples were analyzed on a Vanquish uHPLC equipped with a Q-Exactive Orbitrap (Thermo Fisher Scientific, Waltham, MA, USA). Separation was achieved on a Kinetix Polar C18, $2.6 \mu \mathrm{m}, 100 \times 3.0 \mathrm{~mm}$ column (Phenomenex, Torrance, CA, USA) set at $40^{\circ} \mathrm{C}$ using a gradient (Table 3) with $0.1 \%$ formic acid in water as Mobile Phase A and $0.1 \%$ formic acid in methanol as Mobile Phase B. Injection volume was $1 \mu \mathrm{L}$ and flow rate was $0.5 \mathrm{~mL} / \mathrm{min}$. The DAD was set to store at 215, 230, 250, and $280 \mathrm{~nm}$. The Q-Exactive was operated in full scan as well as full scan product ion modes. Positive ESI was used for all analyses. Spray voltage was set at $4000 \mathrm{~V}$, capillary
Table 3. Gradient conditions for HR-LCMS orbitrap analysis.

\begin{tabular}{lcc}
\hline Time & \% Mobile Phase A & \% Mobile Phase B \\
\hline 0 & 95 & 5 \\
4.5 & 40 & 60 \\
12 & 0 & 100 \\
14 & 0 & 100 \\
14.1 & 95 & 5 \\
\hline
\end{tabular}

temperature was $320^{\circ} \mathrm{C}$, sheath gas at 10 units, auxiliary gas at 40 units, probe heater at $30^{\circ} \mathrm{C}$ and S-lens level at 50 .

\section{Isolation, Structural Elucidation and Activity Testing of Undeclared Compound}

Sixteen capsules from the U-Dream Full $450 \mathrm{mg}$ product, lot number UDF008, were opened and the contents pooled. Approximately $30 \mathrm{mg}$ of the material was weighed into a test tube with $600 \mu \mathrm{L}$ water and $1400 \mu \mathrm{L}$ methanol and placed in an ultrasonic water bath for 10 minutes. The liquid portion was then filtered through a $0.2-\mu \mathrm{m}$ syringe filter into HPLC vials. Samples were injected into an Agilent 1100 HPLC equipped with a quaternary pump, auto-sampler, column compartment, diode array detector and Gilson FC203B fraction collector. Separation was achieved with a Phenomenex Kinetex C18 $5 \mu \mathrm{m}, 100 \times 4.6 \mathrm{~mm}$ column (Phenomenex, Torrance, CA, USA) using a gradient of $5 \% \mathrm{~B}$ at $0 \mathrm{~min}$., $40 \% \mathrm{~B}$ at $6.0 \mathrm{~min} ., 90 \% \mathrm{~B}$ at $9.3 \mathrm{~min} ., 5 \% \mathrm{~B}$ at $10.0 \mathrm{~min}$., with $0.1 \%$ formic water as Mobile Phase A and $0.1 \%$ formic acid in methanol as Mobile Phase B. Injection volume was $10 \mu \mathrm{L}$ with a flow rate of $1.6 \mathrm{~mL} / \mathrm{min}$ and detector set to store signals at 210,254, 280, 330 and $510 \mathrm{~nm}$. The peak eluting at $5.2 \mathrm{~min}$. was collected with the fraction collector programmed to collect in a time window from 5.1 to $5.7 \mathrm{~min}$. Fractions from multiple runs were pooled together and dried under nitrogen for further evaluation.

A portion of the pooled isolated fraction was dissolved in chloroform- $\mathrm{d}$ and transferred through a glass wool filter to an NMR tube for analysis using a Bruker AVANCE 400 spectrometer equipped with Bruker Topspin software (Bruker, Ltd, Milton, ON, CAN). ${ }^{1} \mathrm{H}$ and two dimensional DFQ-COSY NMR experiments were conducted with chemical shift values presented in $\delta(\mathrm{ppm})$ and referenced to the residual solvent signal of $\mathrm{CDCl}_{3}$. NMR data files were processed and analyzed using Mnova 11.0.4 (Mestrelab Research, Escondido, CA, USA).

Commercial zopiclone/eszopiclone ELISA kits were purchased from Neogen (Lexington, KY, USA). The U-dream samples were analysed using these kits as per 
the manufacturer's instructions. Briefly the sample was dissolved in the EIA Buffer from the test kit. The samples were further diluted $1 / 10,1 / 50,1 / 100$, and $1 / 200$ as needed. Drug enzyme conjugates are added into each well along with samples, standards, or controls and incubated at room temperature for $45 \mathrm{~min}$. Each well is then washed three times with $300 \mu \mathrm{L}$ of wash buffer from the test kit. $100 \mu \mathrm{L}$ of K-Blue substrate from the test kit is then added to each well and incubated for 30 minutes at room temperature. The enzyme reaction is stopped by adding $100 \mu \mathrm{L}$ of Acid Stop and then gently mixed before measuring their absorbance at $450 \mathrm{~nm}$ using a Thermo Scientific Multoskan Go Variable Wavelength microplate reader (Thermo Fisher Scientific, Waltham, MA, USA).

\section{Results}

\section{Mass Spectral Analysis for Lorazepam}

Neither lorazepam nor lorazepam glucuronide were detected in the sample using the described method. Examination of the mass spectral acquisition analysis in Mass Hunter to find discrete chemical entities revealed the presence of a prominent peak showing a halogen isotope cluster suggesting the presence of a brominated compound (Figure 2).

\section{HR-LCMS Screening for Undeclared Compounds}

Full scan positive ESI data were acquired from each of the U-Dream products using the Q-Exactive Orbitrap. For both products lots, the compound detected in

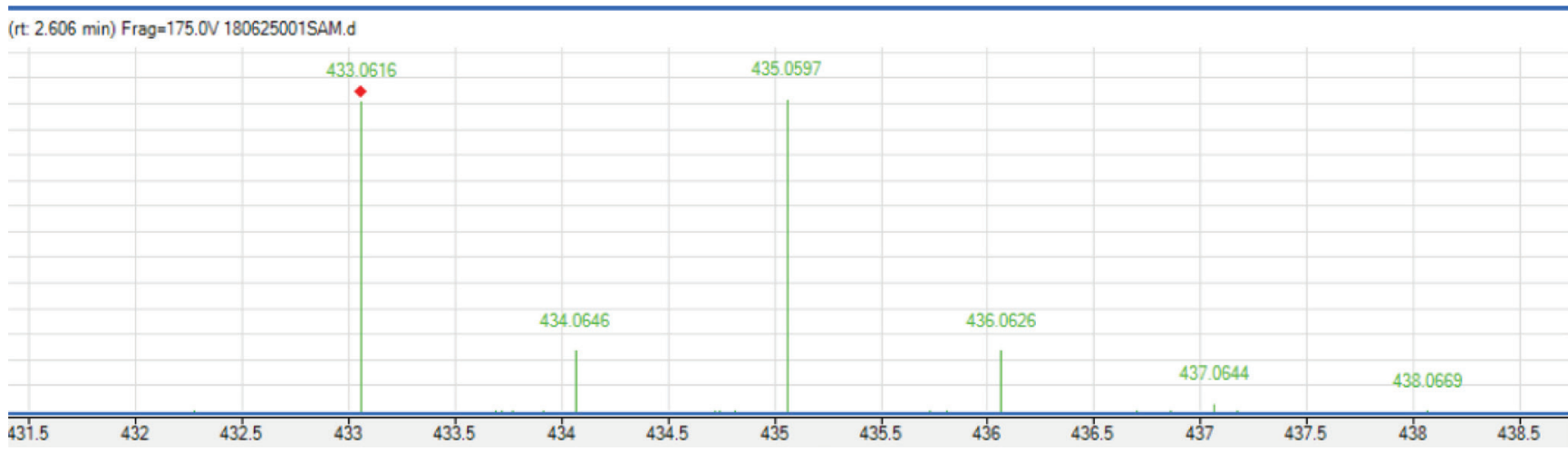

Figure 2. Full scan accurate mass spectrum of unknown peak showing characteristic bromine isotopic pattern.

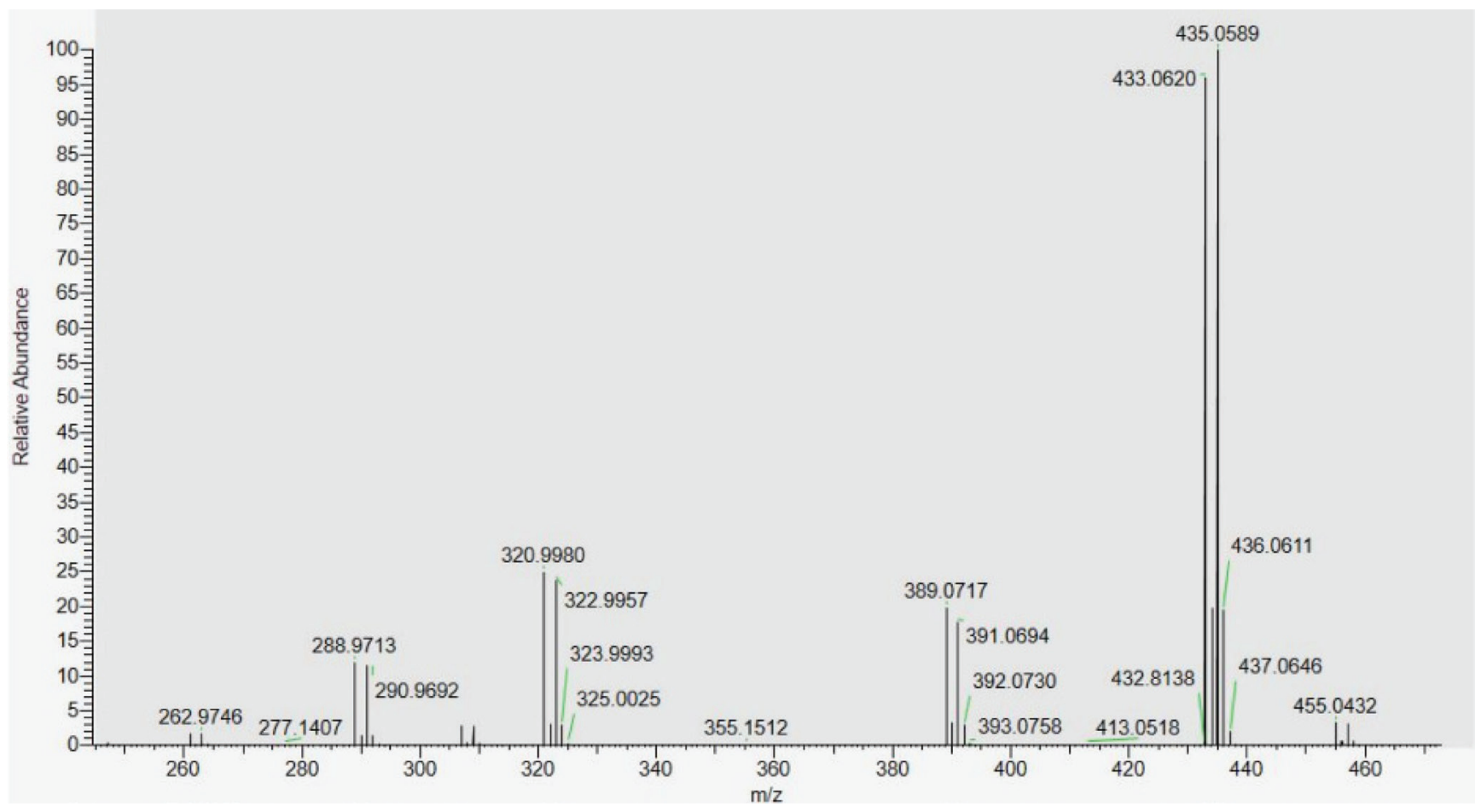

Figure 3. Full scan mass spectrum of peak eluting at 3.9 minutes in the HR-LCMS Orbitrap analysis of the U-Dream product. 
the initial screen was identified as a prominent peak at $3.94 \mathrm{~min}$ in the TIC. The full scan mass spectrum of this compound is shown in Figure 3. The spectrum shows the $\mathrm{H}^{+}$-adduct at $433.0620 \mathrm{~m} / z$ and the associated $\mathrm{Na}^{+}$-adduct at $455.0432 \mathrm{~m} / z$ as well as ions at $435.0589 \mathrm{~m} / z$ and $457.0410 \mathrm{~m} / z$. The near $1: 1$ ratio and mass differences between these adducts and the ions at $435.0589 \mathrm{~m} / z$ and $457.0410 \mathrm{~m} / z$ provides strong evidence for the presence of a single bromine atom in this compound. This identification is further supported by the presence of similar isotopic ratios for other in-source fragmentation products observed in the full scan mass spectrum shown in Figure 3.

The theoretical mass spectra of several known halogen-containing compounds with sedative activity, were compared against the mass spectrum of the unknown compound. It was observed that the substitution of the bromine atom in the observed mass for the unknown compound with a chlorine atom would result in a mass of $389 \mathrm{~g} / \mathrm{mol}$. As the unknown compound is represented in the mass spectra as an $\mathrm{H}^{+}$-adduct at $433.0620 \mathrm{~m} / z$ and an $\mathrm{Na}^{+}$-adduct at $455.0432 \mathrm{~m} / z$ the target mass of the analogue drug would have a mass of $388 \mathrm{~g} / \mathrm{mol}$ which is consistent with the known prescription drug zopiclone (monoisotopic mass $388.1051 \mathrm{~g} / \mathrm{mol}$ ), shown in Figure 4 along with the suggested structure of the unknown compound.

The major fragmentation $\mathrm{m} / \mathrm{z}$ values for several chlorine-containing drug compounds were obtained from MassBank [20]. The reference data was then compared to the observed fragments from the unknown, recalculated to account for the substitution of the chlorine atom with a bromine atom. In Table 4 the calculated modified reference $\mathrm{m} / \mathrm{z}$ values for zopiclone fragments is compared with the observed fragments in mass spectrum of the unknown compound, following $\mathrm{MS}^{2}$ analysis on the $433 \mathrm{~m} / z$ product ion.

Retrospective analysis of the full spectrum scan for the peak also showed $A+2$ ions at near a 1:1 ratio, corresponding to the major $\mathrm{m} / \mathrm{z}$ ions suspected to contain bromine atoms, including ions at 157.9, 184.9, 290.9, 291.9, 308.9, 322.9 and 391.0.

\section{Isolation, Structural Elucidation and Activity Testing of Undeclared Compound}

The pooled fraction isolated by HPLC containing the compound of interest was analyzed by NMR and the one-dimensional ${ }^{1} \mathrm{H}$ spectra is shown in Figure 5.

The presence of a large water signal at $1.6 \mathrm{ppm}$ and several other signals indicated the fraction was not pure, however several hallmark signals were observed that are indicative of aromatic protons, consistent with the structure proposed in Figure 4. The NMR spectrum showed a series of doublets in the range of 7.95-8.92 ppm that were assigned to protons in pyridyl and pyrazinyl rings

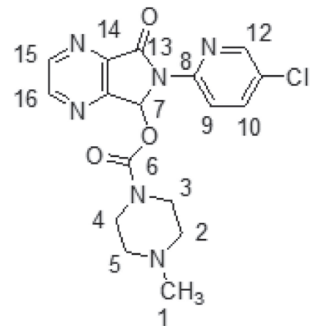

B

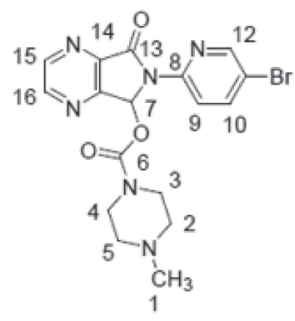

Figure 4. Structure of zopiclone (A) and proposed structure of the suspected brominated analogue found in the product (B).

Table 4. Comparison of major $\mathrm{m} / \mathrm{z}$ for zopiclone reported in Massbank [20], theoretical $\mathrm{m} / \mathrm{z}$ for a zopiclone compound with its chlorine replaced with a bromine atom and observed $\mathrm{m} / \mathrm{z}$ observed from the MS/MS analysis of the $433 \mathrm{~m} / \mathrm{z}$ product ion in the U-Dream product.

\begin{tabular}{|c|c|c|c|c|}
\hline \multicolumn{2}{|c|}{ m/z (MassBank EQ364303) } & \multicolumn{2}{|c|}{ Theoretical $m / z \mathrm{Cl}$ replaced with $\mathrm{Br}$} & \multirow{2}{*}{$\begin{array}{c}m / z \text { observed in U-Dream product } \\
\qquad m / z\end{array}$} \\
\hline$m / z$ & Annotation & $m / z$ & Annotation & \\
\hline 98.0835 & $\mathrm{C} 5 \mathrm{H} 10 \mathrm{~N} 2+$ & 98.0835 & $\mathrm{C} 5 \mathrm{H} 10 \mathrm{~N} 2+$ & 98.0843 \\
\hline 99.0917 & $\mathrm{C} 5 \mathrm{H} 11 \mathrm{~N} 2+$ & 99.0917 & $\mathrm{C} 5 \mathrm{H} 11 \mathrm{~N} 2+$ & 99.0921 \\
\hline 111.9949 & $\mathrm{C} 5 \mathrm{H} 3 \mathrm{CIN}+$ & 155.94438 & $\mathrm{C} 5 \mathrm{H} 3 \mathrm{BrN}+$ & 155.9446 \\
\hline 139.0059 & $\mathrm{C} 6 \mathrm{H} 4 \mathrm{CIN} 2+$ & 182.95538 & $\mathrm{C} 6 \mathrm{H} 4 \mathrm{BrN} 2+$ & 182.9550 \\
\hline 143.0816 & $\mathrm{C} 6 \mathrm{H} 11 \mathrm{~N} 2 \mathrm{O} 2+$ & 143.0816 & $\mathrm{C} 6 \mathrm{H} 11 \mathrm{~N} 2 \mathrm{O} 2+$ & 143.0815 \\
\hline 217.1085 & $\mathrm{C} 11 \mathrm{H} 13 \mathrm{~N} 4 \mathrm{O}+$ & 217.1085 & $\mathrm{C} 11 \mathrm{H} 13 \mathrm{~N} 4 \mathrm{O}+$ & 217.1081 \\
\hline 245.0226 & $\mathrm{C} 11 \mathrm{H} 6 \mathrm{ClN} 4 \mathrm{O}+$ & 288.97208 & $\mathrm{C} 11 \mathrm{H} 6 \mathrm{BrN} 4 \mathrm{O}+$ & 288.9713 \\
\hline 247.0381 & $\mathrm{C} 11 \mathrm{H} 8 \mathrm{ClN} 4 \mathrm{O}+$ & 290.98758 & $\mathrm{C} 11 \mathrm{H} 8 \mathrm{BrN} 4 \mathrm{O}+$ & 290.9870 \\
\hline 263.0332 & $\mathrm{C} 11 \mathrm{H} 8 \mathrm{CIN} 4 \mathrm{O} 2+$ & 306.98268 & $\mathrm{C} 11 \mathrm{H} 8 \mathrm{BrN} 4 \mathrm{O} 2+$ & 306.98201 \\
\hline 277.0487 & $\mathrm{C} 12 \mathrm{H} 10 \mathrm{CIN} 4 \mathrm{O} 2+$ & 320.99818 & $\mathrm{C} 12 \mathrm{H} 10 \mathrm{BrN} 4 \mathrm{O} 2+$ & 320.9980 \\
\hline 345.1227 & $\mathrm{C} 16 \mathrm{H} 18 \mathrm{CIN} 6 \mathrm{O}+$ & 389.07218 & $\mathrm{C} 16 \mathrm{H} 18 \mathrm{BrN6O}+$ & 389.0717 \\
\hline
\end{tabular}




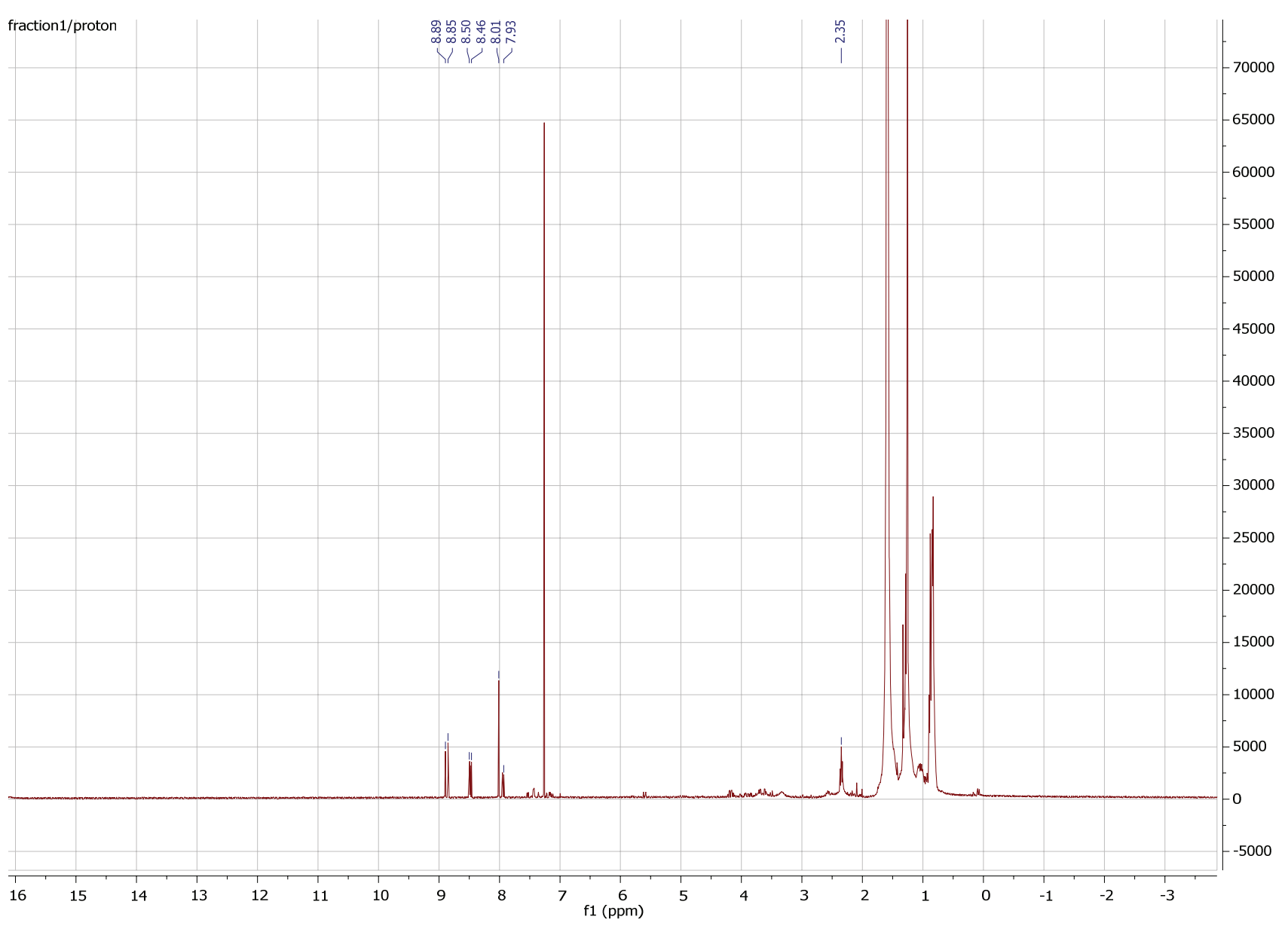

Figure 5. ${ }^{1} \mathrm{H}$ NMR spectrum of fraction obtained from suspected adulterated product.

(Figure 5). Observation of correlations of the 8.89 and $8.85 \mathrm{ppm}$ signals as well as with the $8.52,8.48$ and 7.95 ppm signals in ${ }^{1} \mathrm{H}-{ }^{1} \mathrm{H}$ COSY spectrum further confirmed these assignments (Figure 6). The isolated fraction tested positive in a commercial zopiclone/ eszopiclone ELISA kit.

\section{Discussion}

Several studies performed over the last decade have shown intentional adulteration of natural health products and dietary supplements by the addition of pharmaceutical drugs [9-14]. Certain categories of products are often found to be adulterated, including products for weight loss, body building, erectile dysfunction, sleep problems, inflammatory conditions and metabolic disorders [8-13]. The complex matrices of these products can be analytically challenging for detection of the adulterants [13-15]. Further the use of analogs of those substances, with potentially unknown safety or pharmacological activity, not only makes detection very difficult, it renders the products themselves an unquantifiable public health risk $[14,15]$.
The reports of effects in consumers, not typically associated with the herbal ingredients listed on the U-Dream label, prompted an investigation that began with screening for known pharmaceutical drugs. The combination of the characteristic bromine isotope pattern observed in full scan accurate mass spectrum suggested the presence of a halogenated compound and prompted further investigations. From the MS/MS analysis of the $433 \mathrm{~m} / z$ product ion found in the U-Dream product it was observed the aligned fragmentation pattern (Table 4) of the unknown adulterant was consistent with a brominated analogue of the pharmaceutical sedative zopiclone.

To support the putative identification from the mass spectra studies, the compound was isolated and structure elucidated using ${ }^{1} \mathrm{H}$ NMR. In Figure 5 we show the one-dimensional proton NMR of the unknown. A lack of resolution in the aliphatic region of the ${ }^{1} \mathrm{H}$ NMR spectrum made assignment of the piperazinyl protons difficult and overall the intensity of the signals was lower than expected. These observations suggest that the fraction may have contained degradation products and impurities that were likely created over the course 


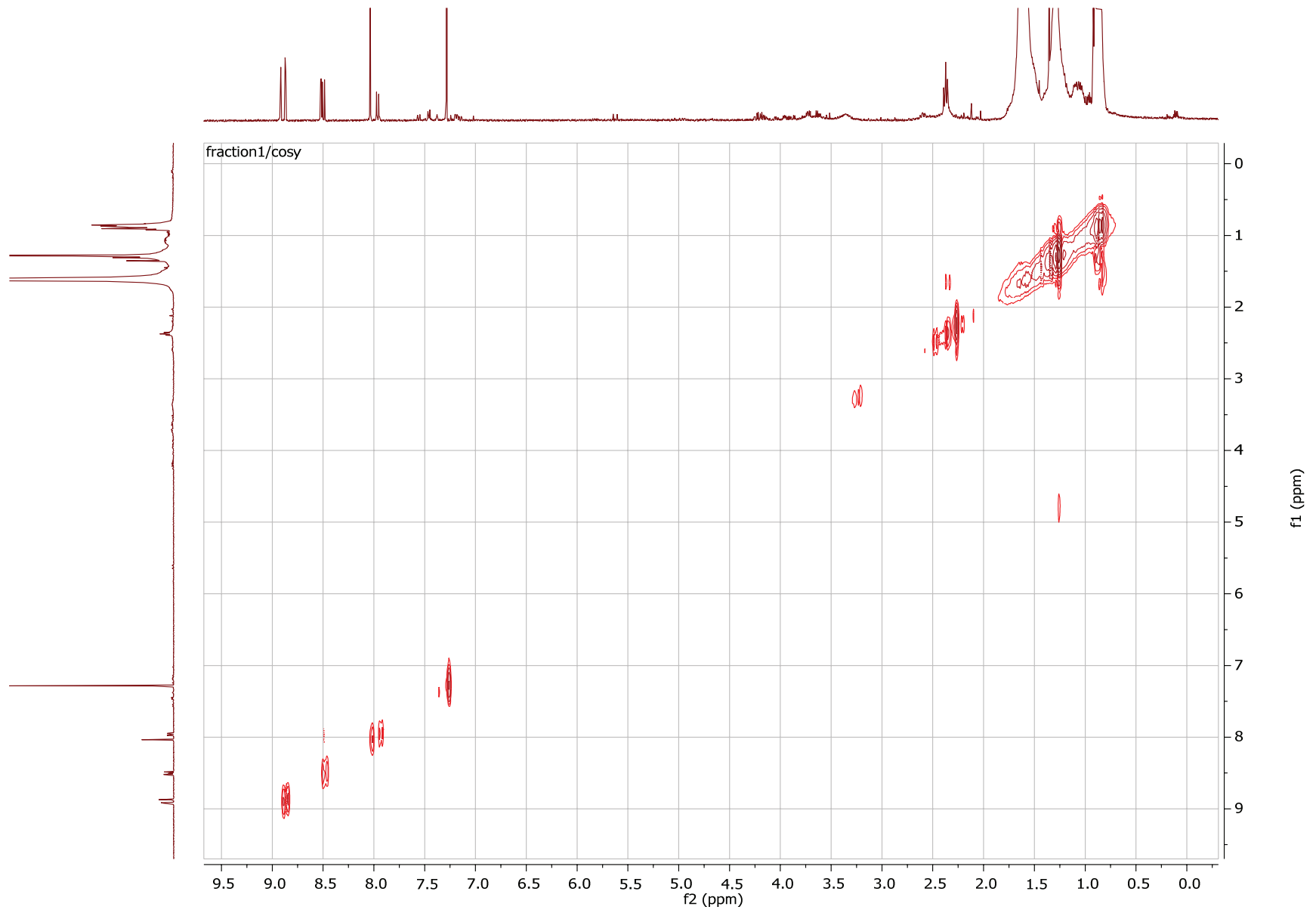

Figure 6. ${ }^{1} \mathrm{H}-{ }^{1} \mathrm{H}$ COSY NMR spectrum of fraction obtained from suspected adulterated product.

Table 5. Comparison of NMR data for the aromatic region reported for zopiclone and the analysis of the isolated fraction. Zopiclone chemical shifts were reported in Ming et al., 2007 [21]. Assignment numbers refer to the numbered atoms in Figure 3.

\begin{tabular}{|c|c|c|c|c|c|}
\hline $\begin{array}{l}{ }^{1} \mathrm{H} \text { chemical shifts } \\
\text { reported for zopiclone } \\
\delta_{\mathrm{H}} \text { in ppm }\end{array}$ & $\begin{array}{c}{ }^{1} \mathrm{H} \text { chemical shift observed } \\
\text { for fractionated sample } \\
\delta_{\mathrm{H}} \text { in ppm }\end{array}$ & $\begin{array}{l}\text { Coupling } \\
\text { constant } \\
J(H z)\end{array}$ & Assignment & Multiplicity & $\begin{array}{l}{ }^{1} \mathrm{H}-{ }^{1} \mathrm{H} \text { COSY } \\
\delta \mathrm{H} \text { in ppm }\end{array}$ \\
\hline 8.85 & 8.89 & 2.5 & 15 & $d$ & 8.85 \\
\hline 8.81 & 8.85 & 2.5 & 16 & $d$ & 8.89 \\
\hline 8.45 & 8.50 & 2.5 & 12 & $d$ & 7.93 \\
\hline 8.32 & 8.46 & 8.9 & 9 & d & 7.93 \\
\hline 7.96 & 8.01 & & 7 & s & \\
\hline 7.74 & 7.93 & $2.5,8.9$ & 10 & $d d$ & $8.46,8.50$ \\
\hline
\end{tabular}

of the isolation experiment. Despite the limitations in the proton NMR spectra obtained for the unknown, the correlations between the 8.89 and 8.85 ppm signals and the 8.52, 8.48 and 7.95 ppm signals in ${ }^{1} \mathrm{H}-{ }^{1} \mathrm{H}$ COSY spectrum further confirmed the assignments. As depicted in Table 5, these assignments compared very well with signals for the published ${ }^{1} \mathrm{H}$ NMR spectra of zopiclone [21]. Similar to the assignments proposed by Ming et al., (2007) the signals in this range, which were integrated for one proton each, were assigned to protons in the pyridyl and pyrazinyl rings. The assignment of the signals to the pyridyl protons were facilitated through the observed multiplet structure and coupling constants as depicted in Table 5.

The assignment of the unknown adulterant as a brominated analogue of zopiclone was further supported by the positive results from the commercial zopiclone/ eszopiclone ELISA kit, indicating that the adulterant is likely biologically active. This finding is particularly concerning as the natural health product tested appears to have been adulterated with an undeclared compound having chemical similarities to a known prescription 
pharmaceutical. It has been noted in the literature that synthesis of a chemically modified analogue of parent drug compounds, can be an effective means to avoid detection $[15,16]$.

Our study demonstrates that using a routine conventional drug screening method which targets specific pharmaceutical drugs, is not effective alone in identifying adulteration. The detection of the undeclared brominated analogue within this product required analysis of the mass spectrum followed by careful evaluation of its mass ion profile. Such a detailed analysis is not typically performed on a routine basis as only the targeted compounds are actively sought for and analysts would seldom have the time to check every single peak in a product that contains multiple herbal ingredients. Furthermore, because ELISA testing of the U-Dream product itself did not produce a positive result, the presence of herbal extracts in the product may have effectively masked the detection of the adulterant with ELISA test kits.

Zopiclone itself is an active pharmaceutical agent that while chemically unrelated to benzodiazepines, binds with high affinity to benzodiazepine receptors [22]. Cautionary statements to patients concerning zopiclone use include hepatic and renal impairment, history of drug use or psychiatric illness and contraindications include myasthenia gravis, respiratory failure, severe sleep apnoea syndrome, severe hepatic impairment, pregnancy and breast-feeding [23]. The most frequently reported adverse event, as cited in the 2006 WHO 34 ${ }^{\text {th }}$ Expert Committee on Drug Dependence, are bitter or metallic taste and dry mouth $[23,24]$. Zopiclone, like many prescriptive sleeping medications, has the potential for abuse and addiction [25]. This risk is higher in patients with a prior history of drug/alcohol abuse or a history of psychiatric illness [26]. In addition, a small number of patients in many clinical trials of zopiclone developed rebound insomnia after discontinuing the drug [25].

Given this compound's structural similarity to zopiclone and the testimonial reports describing adverse events consistent with those reported for zopiclone $[18,19,23]$ it is likely the undeclared analogue has pharmacological activity. However this brominated analogue has not been subjected to pharmacological, toxicological or clinical investigations. "Designer drugs", often referring to the manipulation of the chemical structure of known drugs such that resulting product is structurally similar but not identical, has been a growing concern worldwide [27-29]. Structural analogy with a known pharmaceutical is not alone sufficient to predict function or safety [27]. Although zopiclone is a prescription drug $[30,31]$, rather than an illegal psychoactive drug, as are often the targets of designer drugs, the suspected bromine analogue has no known safety profile and as such poses a substantial public health risk.

\section{Conclusions}

The NHP regulations provide a framework for high quality, safe and efficacious products to access the market in Canada. It is the responsibility of the manufacturer to assure traceability and transparency in their supply chain and establish verifiable compliance with GMP. The NHP U-Dream was suspected of containing an undeclared pharmaceutical based on testimonials of consumers. The experimental mass spectral data indicated the presence of an unknown bromine containing compound in the U-Dream product tested. Based on the fragmentation pattern the unknown was putatively identified as an analogue of zopiclone, whereby the chlorine atom had been substituted with bromine. This assignment was further corroborated by the NMR spectra and positive result from the commercial zopiclone/eszopiclone ELISA kit. The structural characteristics and consumer reviews of the product suggest that this undeclared, unknown compound has pharmacological activity, however to what extent is unknown. Of more considerable concern is the lack of any known safety profile by which to assess consumer risk. This study illustrates the importance of careful evaluation of analytical data in order to detect, not only undeclared adulterants, but unknown chemical entities and highlights the need for active monitoring and surveillance of potentially high-risk products post market entry.

\section{List of Abbreviations}

NHPS: natural health products

NNHPD: natural and non-prescription health products directorate

NPN: natural health product number

HPLC: high performance liquid chromatography

Q-ToF: quadrupole Time-of-Flight

MS/MS: tandem mass spectrometry

$\mathrm{H}_{2} \mathrm{O}$ : water

MeCN: acetonitrile

DAD: diode array detector

ESI: electro-spray ionization

NMR: nuclear magnetic resonance

COSY: correlation spectroscopy

$\mathrm{CDCl}_{3}$ : deuterated chloroform

ELISA: enzyme linked immunosorbent assay

HR-LCMS: high resolution liquid chromatography mass spectrometry

GMP: good manufacturing practice 


\section{Conflicts of Interest}

The authors declare that they have no conflicts of interest.

\section{Authors' Contributions}

PNB: made contributions to the design of the study and substantial contributions to the data analysis and interpretation, drafted the manuscript including critically important intellectual content, gave final approval of the version to be published and as corresponding author agrees to be accountable for all aspects of the work and ensuring that questions related to the accuracy or integrity of any part of the work are appropriately investigated and resolved.

\section{(D) https://orcid.org/0000-0003-4886-7001}

MC: contributed to study design and planning, assisted with the collection and analysis of data, and manuscript preparation. Significantly contributed to the data interpretation, and gave final approval of the version to be published.

\section{(D) https://orcid.org/0000-0003-3180-3263}

CC: made substantial contributions to the design of the study, the collection of data as well as interpretation and analysis of the data, revised the manuscript, and gave final approval of the version to be published.

SK: made substantial contributions to the collection of data, drafting of protocols, and gave final approval for the version to be published.

YSR: made substantial contributions to the design, acquisition, analysis, and interpretation of data, drafting of protocol, and gave final approval for the version to be published.

JN-K: made contributions to the collection of data as well as interpretation and analysis of the data, revised the manuscript including critically important intellectual content, and gave final approval of the version to be published.

MLH: made contributions to study design, the interpretation of the data, critically revised the manuscript, made important intellectual contributions, and gave final approval of the version to be published.

\section{Acknowledgements}

The authors gratefully acknowledge our colleagues at Supra R\&D (Kelowna, BC) and in particular Mathew Noestheden for his technical expertise in performing the high resolution mass spectral studies and insight into the subsequent data interpretation.

\section{Funding}

This research was undertaken, in part, thanks to funding from the Canada Research Chairs Program (PNB).

\section{References}

[1] Government of Canada [Internet]. Natural Health Products Regulations. [Cited August 26, 2019]. Available from: https://laws-lois.justice.gc.ca/eng/regulations/sor2003-196/

[2] Government of Canada [Internet]. About Natural Health Product Regulation in Canada. [Cited August 26, 2019]. Available from: https://www.canada.ca/en/ health-canada/services/drugs-health-products/naturalnon-prescription/regulation.html

[3] Government of Canada [Internet]. Evaluation of the Natural Health Products Program 2010-2011 to 2014-2015, prepared by the Office of Audit and Evaluation, Health Canada and the Public Health Agency of Canada March 2016. [Cited November 19, 2019]. Available from: https://www.canada.ca/ en/health-canada/corporate/transparency/corporatemanagement-reporting/evaluation/2010-2011-20142015-natural-health-products-program.html\#_a3-2

[4] Gilmour J, Harrison C, Asadi L, Cohen MH, Vohra S. Natural health product-drug interactions: evolving responsibilities to take complementary and alternative medicine into account. Pediatrics. 2011;125(4): S155-S160.

[5] Wardle JL, Adams J. Indirect and non-health risks associated with complementary and alternative medicine use: An integrative review. Eur. J. Integr. Med. 2014;6: 409-422.

[6] Liu SH, Chuang WC, Lam W, Jiang Z, Cheng YC. Safety surveillance of tradition chinese medicine: current and future. Drug Safety. 2015;28:117-128.

[7] Metcalf A, Williams J, McChesney J, Patten SB, Jette N. Use of complementary and alternative medicine by those with a chronic disease and the general population - results of a national population-based survey. BMC Complem. Altern. M. 2010;10(58):1-6.

[8] Heinrich M. Quality and safety of herbal medical products: regulation and the need for quality assurance along the value chain. Brit. J. Clin. Pharmaco. 2015;80(1): 62-66.

[9] Health Canada [Internet]. It's Your Health - Adulteration of Natural Health Products. [Cited November 19, 2019]. Available from: http://www.hc-sc.gc.ca/hl-vs/alt_formats/ pdf/iyh-vsv/med/nat-prod-adulter-eng.pdf

[10] Rocha T, Amaral JS, Oliveira MBPP. Adulteration of dietary supplements by the illegal addition of synthetic drugs: A review. Compr. Rev. Food Sci. F. 2016;15:43-62. 
[11] Ekar T, Kreft S. Common risks of adulterated and mislabeled herbal preparations. Food Chem. Tox. 2019;123:288-297.

[12] Calahan J, Howard D, Almalki AJ. Gupta MP, Calderon Al. Chemical adulterants in herbal medicinal products: A review. Planta Med. 2016;82:505-515.

[13] Schramek N, Wollein Q. Chapter 7 adulteration of synthetic substances in dietary supplements. In. Shrivastava A (Ed.). Volume 1 adulteration analysis of some food \& drugs. Benthem Science Publisher; 2018.

[14] Lee JH, Park HN, Choi JY, Kim NS, Park HJ, Park SS, Baek SY. Simultaneous analysis by Quadrupole-Orbitrap mass spectrometry and UHPLC-MS/MS for the determination of sedative-hypnotics and sleep inducers in adulterated products. J. Sep. Sci. 2017;40(24):4677-4688.

[15] Yun J, Choi J, Jo CH, Kwon K. Detection of synthetic anti-obesity drugs, designer analogues and weight- loss ingredients as adulterants in slimming foods from 2015 to 2017. J. Chrom. Sep. Tech. 2018;9(1):1-6.

[16] Lee JH, Park HN, Kim NS, Park S, Lee YM, Kang H. Development of a specific fragmentation pattern-based quadrupole-orbitrap mass spectrometry method to screen drugs in illicit products. Sci. Justice. 2019: https:// doi.org/10.1016/j.scijus.2019.08.001

[17] Health Canada [Internet]. Licensed Natural Health Products Database Search Results for U-Dream. [cited August 26, 2019]. Available from: https://health-products. canada.ca/Inhpd-bdpsnh/search-recherche.do;jsession id=EB871CB40A3C11 F629752E1FFFCEC46E

[18] Amazon.ca [Internet]. U Dream Herbal Sleep Aid Full Night (7/8) hours 10 Capsules. [cited October 8, 2019]. Available from: https://www.amazon.ca/Dream-HerbalSleep-Night-Capsules/dp/B07DF4YRJH/ref=zg_bs_ 6370112011_3?_encoding $=U T F 8 \& p s c=1$ \&refRID = Z8HY008205RM5J3NVWG2

[19] Amazon.com [Internet]. U-Dream All Natural Herbal Supplement to Help You Sleep (Full Night Formula (7/8 Hours)). [cited October 8, 2019]. Available from: https:// www.amazon.com/U-Dream-Natural-Herbal-Supplement-Formula/dp/B07N6KKY7L/ref=sr_1_3?keywords= U-Dream\&qid $=1570557497 \&$ sr $=8-3$

[20] MoNA - MassBank of North America [Internet] Spectrum EQ364301 for Zopiclone. [cited October 8,
2019]. Available from: https://mona.fiehnlab.ucdavis. edu/spectra/display/EQ364301

[21] Ming X, Lian H, Zhu W. Spectral data analyses and structure elucidation of sedative-hypnotic Zopiclone. Instrum. Sci. Tech. 2007;35:349-360.

[22] Blanchard JC, Boireau A, Garret C, Julou L (1979). In vitro and in vivo inhibition by zopiclone of benzodiazepine binding to rodent brain receptors. Life Sci 24: 2417-2420.

[23] WHO Expert Committee on Drug Dependence. 34th ECDD 2006/4.6 Assessment of zopiclone. In. WHO Technical Report Series 942 WHO Expert Committee on Drug Dependence Thirty-fourth Report. World Health Organization; 2006. [cited 2019 November 27]. Available from: https://www.who.int/medicines/areas/ quality_safety/4.6ZopicloneCritReview.pdf?ua=1

[24] Wadworth AN, McTavish D (1993). Zopiclone. A review of its pharmacological properties and therapeutic efficacay as an hypnotic. Drugs Aging 3:441-459.

[25] Cimolai N. Zopiclone is it a pharmacologic agent for abuse? Can. Fam. Physician. 2007;53(12):2124-2129.

[26] Morinan A, Keaney F. Long-term misuse of zopiclone in an alcohol dependent woman with a history of anorexia nervosa: a case report. J. Med. Case Rep. 2010: https:// doi.org/10.1186/1752-1947-4-403

[27] Venhuis BJ, Blok-Tip L, de Kaste D. Designer drugs in herbal aphrodisiacs. Forensic Sci. Int. 2008;177:e25-e27.

[28] Musselman ME, Hampton JP. "Not for human consumption": A review of emerging designer drugs. Pharmacotherapy. 2014;34(7):745-757.

[29] Weaver MF, Hopper JA, Gunderson EW. Designer drugs 2015: Assessment and management. Addic. Sci. Clin. Pract. 2015: https://doi.org/10.1186/s13722-0150024-7

[30] Health Canada. [Internet] Prescription Drugs List. [cited 2019 November 27]. Available from: https://hpr-rps. hres.ca/pdl.php?lang=en

[31] Federal Register. [Internet] Schedules of Controlled Substances: Placement of Zopiclone into Schedule IV. [cited 2019 November 27]. Available from: https://www. federalregister.gov/documents/2005/04/04/05-6703/ schedules-of-controlled-substances-placement-ofzopiclone-into-schedule-iv 


\section{Article Information}

Managing Editor: Kieran Cooley

Peer Reviewers: Frank Jerry LaRonde, Pierre Haddad, John Arnason

Article Dates: Received Dec 06 19; Accepted Mar 09 20; Published Mar 2320

\section{Citation}

Please cite this article as follows:

Brown PN, Chan M, Chang C, Kuo S, Roh YS, Neal-KababickJ, Hardy ML. Detection of Undeclared Halogen Substituted Drug Compound in a Natural Health Product. Journal of Natural Health Product Research. 2020 Mar 23: 2(1). https://jnhpresearch.com/index.php/jnhpr/article/view/8

DOI Link: https://doi.org/10.33211/jnhpr.8

\section{Copyright}

(c) Paula N. Brown, Michael Chan, Chuck Chang, Sheena Kuo, Yoon Seok Roh, James Neal-Kababick, Mary L. Hardy. (2020). Published first in the Journal of Natural Health Product Research. This is an open access article distributed under the terms of the Creative Commons Attribution License (https://creativecommons.org/licenses/by/4.0/), which permits unrestricted use, distribution, and reproduction in any medium, provided the original work, first published in the Journal of Natural Health Product Research, an NHP Publications journal, is properly cited. The complete bibliographic information, a link to the original publication on https://www.jnhpresearch.com, as well as this copyright and license information must be included.

Journal of Natural Health Product Research

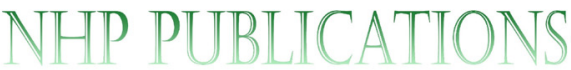

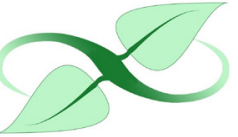

Canadà̀

Does the safety, efficacy, and quality of natural health products matter to YOU? Submit your research article to the Journal of Natural Health Product Research!

Pre-submission inquiries? Send us an email at editorial.office@jnhpresearch.com Facebook, Twitter and LinkedIn: @NHPPublications 